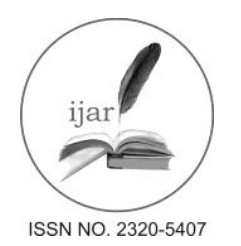

Journal homepage:http://www.journalijar.com

Journal DOI:10.21474/IJAR01

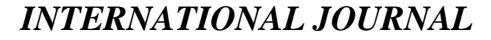

OF ADVANCED RESEARCH

RESEARCH ARTICLE

\title{
STUDY \& REVIEW ON THE PERFORMANCE ANALYSIS OF VARIOUS EXPANSION DEVICES IN VAPOUR COMPRESSION REFRIGERATION SYSTEM
}

\author{
Rohit Joshi ${ }^{1}$, Dr. Atul A. Patil ${ }^{2}$ \& Prof.Tushar A. Koli ${ }^{2}$. \\ 1. Student of Master of Engineering (Thermal) Godavari COE Jalgaon. \\ 2. Department of Mechanical Engineering, Godavari COE Jalgaon.
}

\section{Manuscript Info Abstract}

Manuscript History:

Received: 19 March 2016

Final Accepted: 26 April 2016

Published Online: May 2016

Key words:

Capillary Tube, Thermostatic expansion valve, Ejector expansion, R22, R12, R407C, R744.

*Corresponding Author

Rohit Joshi.
The present review is concerned with the study of the effect of different expansion devices with refrigerant R22, R12, R407C, and R744 on the vapour compression refrigeration system. This paper is concerned with an overview of the project, the fundamental physics underlying the operation of fixed and variable expansion devices which includes capillary tube, thermostatic expansion valve, constant expansion device, Multi ejector expansion, and summarizes results of the analyses performed to compare them. For conducting the experimental verification with different expansion devices and R22, R12, R407C, R744 as refrigerant small test rig is used by many researchers. The experimental analysis conducted by various researchers for small capacity refrigeration systems are selected to study the performance characteristics of capacity of cooling, power required by the compressor, refrigerant mass flow rate and the coefficient of performance (COP) of the vapour compression refrigeration system with respect to different expansion devices like thermostatic expansion valve, Constant expansion valve and capillary tube.

Copy Right, IJAR, 2016, All rights reserved.

\section{Introduction:-}

Expansion device is one of the important part of vapour compression refrigeration system. According to selection of cooling capacity and size of compressor, the expansion device is selected or adjusted. Main function of expansion device is (1) The refrigerant has to overcome the frictional resistance offered by tube walls hence this leads some pressure drop which is necessary between condenser and evaporator. (2) Also, the mass flow rate, Tube Diameter and Area is constant, the velocity of refrigerant increases since $=\rho \mathrm{VA}$. The increase in velocity of the refrigerant also requires pressure drop. The selection of the any expansion device is of particular importance for the operation of vapour compression refrigeration system in efficient manner because it regulates refrigerant flow into the evaporator.COP of the system and efficient working of the compressor is partly depends on the expansion device chosen for the particular system.

\section{Literature Review:-}

Dhumal et. al. [1] studied the effect of R407C refrigerant which is HFC refrigerant on vapour compression refrigeration system with different expansion devices. i. e. Thermostatic expansion valve, Capillary tube of diameter 0.50 " with length $1.5 \mathrm{~m}$ and 0.55 " with length $1.75 \mathrm{~m}$. Experimental setup of $1234 \mathrm{~W}$ capacity was used for analysis purpose. 
The result achieved by this analysis are

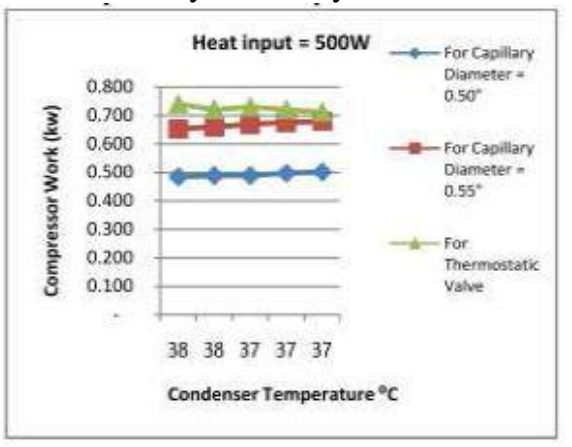

Fig. 1:- Comparison of compressor work at 500W[1]

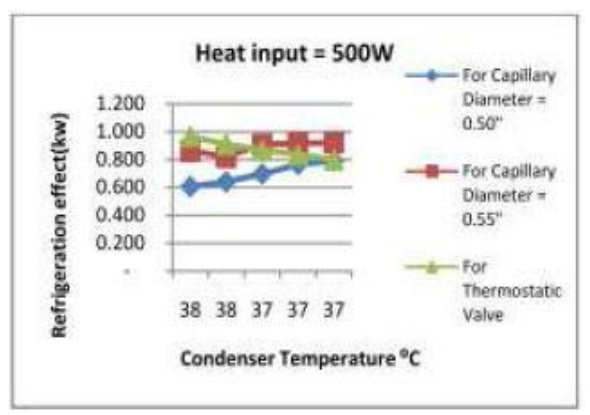

Fig. 3:- Comparison of refrigeration effect at 500W[1]

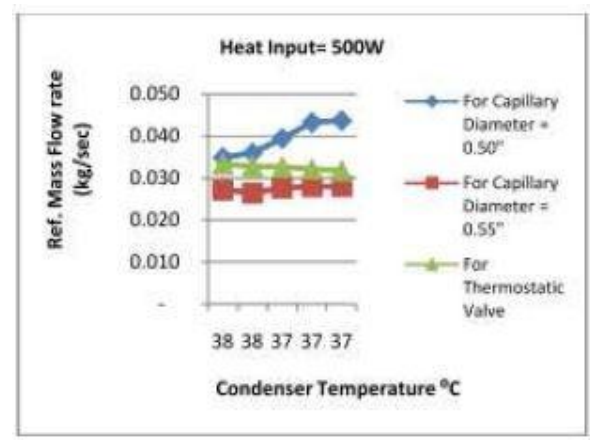

Fig. 2:- Comparison of refrigerant mass flow rate at at

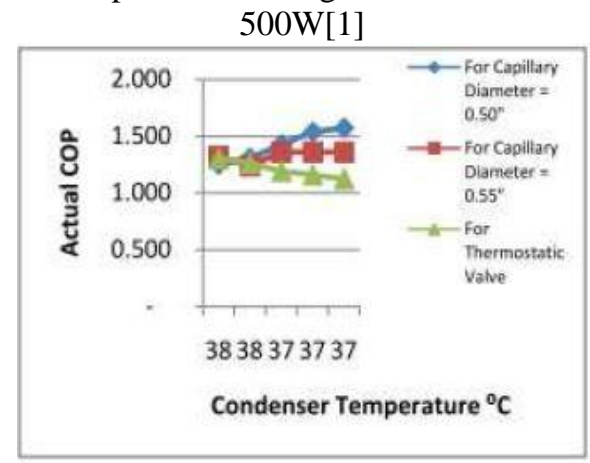

Fig. 4:- Comparison of Actual COP at 500W[1]

Thermostatic expansion valve requires $50 \%$ more work input at all loads load than the capillary tube but the average increase in compressor work with increase in load is $14 \%$ which is much lesser than the capillary tube where it is $75 \%$. The TEV shows $43 \%$ low refrigerant flow rate as compared to capillary tubes and it decreases with increase of load on the system. The capillary with Dia. 0.50 " shows higher mass flow rate of refrigerant and it increases with increase of load on the system. Capillary with Dia. 0.55 " shows steady increase in mass flow rate with load. The increase in refrigerant mass flow rate in TEV is $12 \%$ where as $90 \%$ in capillary tube with Dia. 0.50 ". The TEV gives higher refrigeration effect as compared to other two expansion devices and its performance increases by $86 \%$ at higher loads. The refrigeration effect is increased by only $50 \%$ in capillary tube with increase in load. The rate of heat extraction of the Thermostatic expansion valve is much better than the capillary tubes. Thermostatic expansion valve shows only $12 \%$ increase in refrigerant mass flow rate for $86 \%$ increase in refrigeration effect whereas capillary shows $90 \%$ increase in refrigerant mass flow rate for $50 \%$ increase in refrigeration effect.

MutalubiAkintunde[3] studied the effect of pitch of coiled cap tube on VCR system with R134a. They examined the two configurations of capillary tubes i.e. Helical and Serpentine coils.

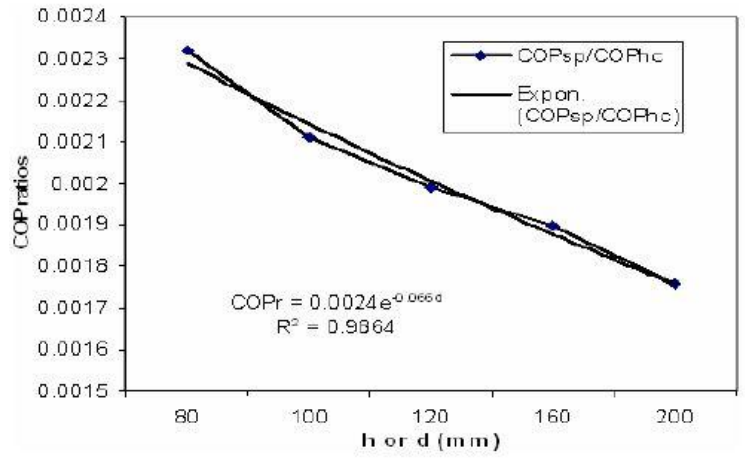

Fig 5:- Variation of COP ratios.
As per their results of performance testing, variations in pitch of coil do not have any significant effect on performance but the diameter of capillary tube coil has effect on performance for helical cap tube.

For serpentine coil capillary tube pitch as well as the coil diameter affects the system performance. When pitch and height increases, the performance of vapour compression refrigeration system increases but size of system also increases so this event is useful for large systems. 
AmolGawaliet. al.[2] has performed the experiment on vapour compression refrigeration system of $0.33 \mathrm{TR}$ and refrigerant used was R12. He used thermostatic expansion valve and Capillary tube for analysis with R12. The analysis focuses on Coefficient of Performance for both (Capillary tube and Thermostatic expansion valve). The Carnot, Theoretical and Actual Coefficient of Performance was checked.

The results of Coefficient of Performance obtained are plotted below in the form of bars.

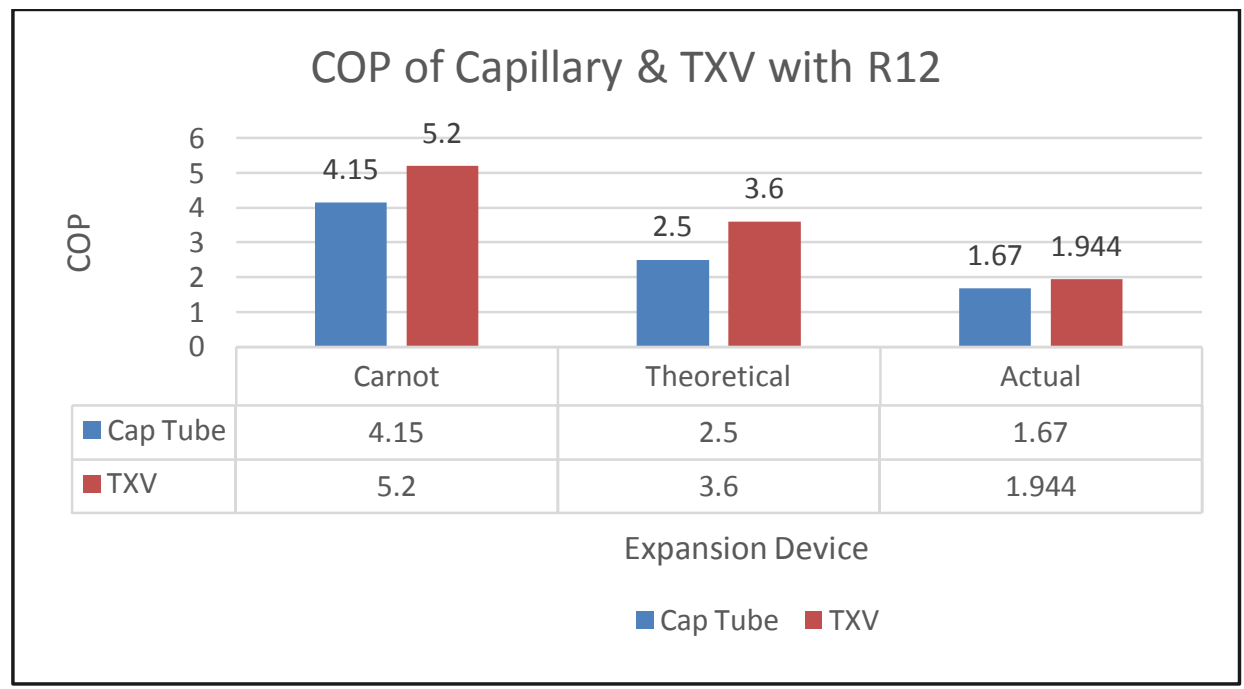

Fig 6:- COP of Capillary \& TXV with R12 [2]

To provide energy saving a TXV equipped VCR system is provided. TXV adjusts the minor pressure difference in the charged R12 refrigerant. Capillary tube provides constant expansion so it do not have the compensating ability for changes in load. With Thermostatic Expansion, the returning of refrigerant to compressor is improved so possibility of liquid slugging is avoided with better cooling at high temperature. Also, the work required by TXV is less than that of the capillary tube.

R. Lazzarinet. al.[4] compared the electronics expansion device with thermostatic expansion device experimentally. According to their experiment, in the air conditioning plant, the use of electronic expansion valve instead of thermostatic expansion valve saves the energy significantly. They analysed the eight direct expansion system of air conditioners with the total capacity of $120 \mathrm{~kW}$ which is installed in telephone control room. (Bolonga, North Italy). Solenoid controls was used for activating the expansion devices on daily basis.

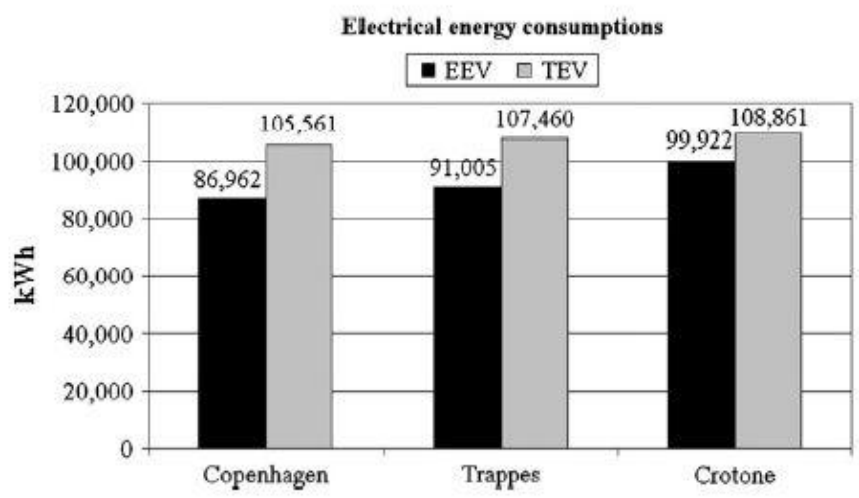

Fig 7:-Annual electrical energy consumptions for the three European climates [4] 
Consumption of electrical energy in kWh was studied in three European atmospheric conditions i.e. Copenhagen, Trappes, Crotone. By the use of electronic expansion valve, according to Lazzarin's experiment following are the benefits obtained:

* At the outlet of evaporator, superheating is lower

* operation is steadier

* When low condensation pressure is available, mass flow rate is higher.

For higher mass flow rate, Electronic expansion device has steady operation \& Thermostatic expansion valve has on-off arrangement.

Krzysztof Banasiaket. al.[9] studied the multi ejector expansion system for R744 vapour compression units on system rated for $70 \mathrm{~kW}$ at 35 degree Celsius outlet temperature of gas cooler and -3 degree Celsius of evaporator temperature for four cartridge sized for ejectors system and this system was analyzed \& verified experimentally. Multi ejector block system retains the dynamic operational characteristics and precise control of discharge pressure with load variations and atmospheric conditions.

\section{Summary:-}

As per the study of various scientists,

1. The use of electronic expansion device provides steady operation than thermostatic expansion valve.

2. Thermostatic expansion valve performs well than cap tube for variable load conditions.

3. For serpentine coil capillary tube pitch as well as the coil diameter affects the system performance.

4. For helical coil, pitch as well as the coil diameter do not affect the performance.

5. When ejector pack with R744 is used instead of high pressures expansion device, gives better performance and operational characteristics.

\section{References:-}

1. A. H. Dhumal, H. M. Dange (2014).Investigation of influence of the various Expansion devices on the performance of a Refrigerator using R407C refrigerant. Int J AdvEngg Tech/Vol. V/Issue II/April-June,2014 96-99

2. Amol A. Gawali, Madhav S. Joshi, Rupesh L. Raut, Rahul A. Bhogare (2014). Experiment analysis and performance testing of Capillary tube and thermostatic expansion valve. International journal of science, engineering and technology. ISSN: 2348-4098 Volume 02 ISSUE 05 JUNE 2014

3. MutalubiAremuAkintunde (2007) Effect of Coiled Capillary Tube Pitch on Vapour Compression Refrigeration System Performance, AU J.T. 11(1): 14-22 (Jul. 2007)

4. R. Lazzarin, M. Noro (2007) Experimental comparison of electronic and thermostatic expansion valves performances in an air conditioning plant. International Journal of Refrigeration ( 2008 ) 113-118

5. OrhanEkren, SavasSahin, YalcinIsler (2010)Comparison of different controllers for variable speed compressor and electronic expansion valve. International Journal of Refrigeration. 33 ( 2010 ) 116 1-1168

6. Erik Bjork, Bjorn Palm (2007) Performance of a domestic refrigerator under influence of varied expansion device capacity, refrigerant charge and ambient temperature. www.elsevier.com/locate/ijrefrig

7. Ian W. Eames, Adriano Milazzo, Graeme G. Maidment. (2013) Modelling thermostatic expansion valves. International Journal of Refrigeration.38 (2014 ) 189-197

8. Zhen Tian, Bo Gu, Cheng Qian, Lin Yang, Fen Liu (2015) Electronic expansion valve mass flow rate prediction based on dimensionless correlation and ANN model. 57(2015) 1-10

9. Krzysztof Banasiak, Armin Hafner, Ekaterini E. Kriezi, Kenneth B. Madsen, Michael Birkelund, Kristian Fredslund, Rickard Olsson. (2015)Development and performance mapping of a multiejectorexpansion work recovery pack for R744 vapour compression units. International Journal of Refrigeration. 57 (2015) 265-276.

10. DembaNdiaye, Michel Bernier (2008)Modelling the bleed port of a thermostatic expansion valve. International Journal of Refrigeration.32 (2009) 826-836.

11. Alessandro Beghi, Luca Cecchinato, MircoRampazzo.(2010) On-line, auto-tuning control of Electronic Expansion Valves.International Journal of Refrigeration34 (2011) 1151-1161.

12. B. Saleh, Ayman A. Aly. (2015)Artificial neural network models for depictingmass flow rate of R22, R407C and R410A through electronic expansion valves 63 (2016) 113-124. 